\title{
Capabilities of Hyperspectral Remote Sensing Data to Detect Soil Salinity
}

\author{
Abdelrahman Medhat ${ }^{1}$, Yasser M Zakarya ${ }^{1}$, Mohammed S Abd-Elwahed ${ }^{1}$, \\ Sayed M Arafat ${ }^{2}$ \\ 1- Soil and Water Department, Faculty of Agriculture, Ain Shams University, Cairo, Egypt, P.O. Box 68, \\ Hadyek Shoubra 11241, Cairo, Egypt \\ 2- Agric Appl, Soils and Marine Division, National Authority for Remote Sensing and Space Sci, (NARSS), \\ Cairo, Egypt \\ * Corresponding author: abdelrahman2@agr.asu.edu.eg \\ DOI:10.21608/ajs.2021.87863.1402
}

Received 29 July, 2021 ; Accepted 7 December, 2021

\section{Keywords:}

Soil salinity, Hyperspectral, Remote sensing, PLSR model

\begin{abstract}
The objectives of the current study were to investigate the opportunity of estimating soil salinity from hyperspectral data and identifying the most informative spectral zones for estimation. Electrical conductivity (EC) measurements of ninety topsoil samples $(0-30 \mathrm{~cm})$ collected fromToshka, Egypt, were used as data set. Analytical spectral device was employed to collect the reflectance spectral signatures of soil samples. Both linear regression and HSD Tukey's analyses displayed that the SWIR1 and SWIR2 zones are the most suitable for soil salinity prediction while, blue, green and NIR were the wickedest. Moreover, EC estimation was better in case of lower soil salinity $\left(0-2 \mathrm{dS} \mathrm{m}^{-1}\right)$ than higher levels $\left(8<\mathrm{dS} \mathrm{m} \mathrm{m}^{-1}\right)$. Partial-least-squaresregression (PLSR) was employed to establish soil salinity prediction model using the training set of soil samples $(\mathrm{n}=75)$. The PLSR model was set up using the most informative wave bands (SWIR1 and SWIR2). The result showed that PLSR linear model gave a precise prediction of soil salinity $\left(\mathrm{R}^{2}\right.$ $=0.93$ ). The results revealed that employing reflectance values in SWIR in the model variables increases the precision of soil EC prediction.
\end{abstract}

\section{Introduction}

Soil salinization problems mostly show up because of the accumulation of salts in soil, which move up and precipitate at the soil surface. According to Aldabaa et al (2015) and Pessoa et al (2016) salts accumulate in soils often from either geological formation including (halite, shale and gypsum) or anthropogenic practices. Dehaan and Taylor (2002) mentioned that various factors may cause soil salinization, while the most important factor like the upward movement of salty water to soil surface. The salts usually accumulate in surface soils because of capillary rise. Subsequently, the signs of increasing salts content at surface layer are possible to be varied because of the factors that influence the extent of salinization are witnessed at soil surface.

On the other hand, for better soil management, operative agricultural management plans are needed especially in semi-arid and arid areas. Fast and steady soil salinity monitoring is vital for making such effective plans (Pessoa et al 2016).

During the last two eras several researchers have studied the capabilities of remote sensing data for monitoring and estimating various soil properties in various countries (Poggio and Gimona 2017, Xu et al 2018, Angelopoulou et al 2020, Mahajan et al 2021). 
Remote sensing uses the different sensors data from space to detect salinization. The sensors record the amount of returned electromagnetic energy from the sensed targets. The wavelengths ranged between 400 to $2400 \mathrm{~nm}$ are frequently used for different resources studies. The incidence of salts at the soil could be sensed using remote sensing data in following two approaches; direct way on barren soils, using the efflorescence of the crusted salts, or through detecting the reflectance spectra of the growing vegetation as these are or affected by salinity (Abd-Elwahed 2005).

Several studies used remote sensing data to study extremely saline soils while disregarding soils with low salt content, which should be the primary focus of soil deterioration research Monitoring and evaluation of low soil salinity values is considered difficult, which mostly related to the quality and the nature of remote sensing sensors. The data type and quality usually do not allow collecting information on soil depth (third dimension). Moreover, the consequence of salinity on electromagnetic features requires more investigations to recognize how it can be related and estimated from remote sensing data Farifteh and Farshad (2002).

Hyperspectral remote sensing information is mostly related with the target properties and sensors type (Richards and Jia 2006, Camps-Valls et al 2011). Hyperspectral remote sensing has high potential and progressively employed in various applications (for example: food safety, quality control and for quantitative assessment of soil and vegetation attributes) (Minu et al 2016).

The results of Dwivedi and Sreenivas, (1998), Abd-Elwahed (2005), Singh et al (2017) established the importance of remote sensing procedures in soil salinity monitoring and detection. According to Singh et al (2017), some spectral confusion may be occurred when dealing with soil salinity. The key reason of spectral misperception was the confusion of various salinity levels with soil textures, land cover, and calcium carbonate content. Moreover, reflectance declines, and detecting salts became difficult with increasing soil water content, and the occurrence of iron oxides. Likewise, the incidence of $\mathrm{OH}^{-}$groups reducing the reflectance in both MIR and NIR spectral ranges (Mougenot et al 1993 and Minu et al 2016). Positive results were obtained by Ben-Dor et al (2002), Hu et al (2019), Schreiner et al (2021) in employing the hyperspectral data to study soil salinity and produce salinity maps.
Under laboratory condition, Csillag et al (1993) recognized six spectral bands (shortwave-infrared, Near-Infra-Red and visible bands) related to different salinity levels of the soils under salinization and alkalization developments using modified stepwise principal component analysis band selection methodology.

According to Abd-Elwahed (2005) most of the investigations used remote sensing approaches discriminate few classes of soil salinity (less than 4 classes). Generally, highly saline zones are simply identified, whereas low-salinity stages and the early phases of soil salinity are more problematic to discriminate.

Recently, Bannari et al (2018) studied the hypersaline soils in the United Arab Emirates to find the correlation amongst soil salinity values and the soil samples spectral reflectance. They analyzed hyperspectral signatures and figured out a new exceptional anhydrite calcium sulfate rich soil inside the hypersaline coastal soil in the United Arab Emirates which resulted the addition of a new soil type into the USDA-Soil Taxonomy.

The main objective of the current investigation is to determine the most sensitive, treasured spectral bands that could be used in estimating soil salinity.

\section{Materials and Methods}

\subsection{Soil sampling and laboratory analysis}

Following 250-meter symmetric grid, 120 sampling locations were set (Fig 1) and 365 soil samples (Including surface and subsurface samples) were collected. The soil samples registered using a hand-held global positioning system (GPS) "MAGELLAN-GPS NAV DLX-10 TM". From the 365, a total of 90 surface soil samples were selected for this study. Electrical conductivity (ECe) was determined according to Jackson (1967), in soil paste extract using EC-meter (Consort C932) expressed in $\mathrm{dSm}^{-1}$.

\subsection{Reflectance measurements}

The air-dried soil samples were passed through a 2-mm sieve and then laboratory spectral measurements were performed. The reflectance spectra of the soil samples were recorded using a Full Range Analytical Spectrum Device (ASD Field-Spec 4) with $8^{\circ}$ field of view (FOV). Each soil sample covered the entire device FOV. Reflectance values were recorded in a full optical spectral range $350-2500 \mathrm{~nm}$. The spectral region 350-1050 $\mathrm{nm}$ has $1.4 \mathrm{~nm}$ sampling interval, while it was $2 \mathrm{~nm}$ in the spectral region of 1000-2500 $\mathrm{nm}$. The resulted data has one nanometer interval for the $350-2500 \mathrm{~nm}$ range. The spectrum specifications of the ASD (ASD, Boulder, CO, United States) are shown in Table 1 (Pimstein et al 2011). 


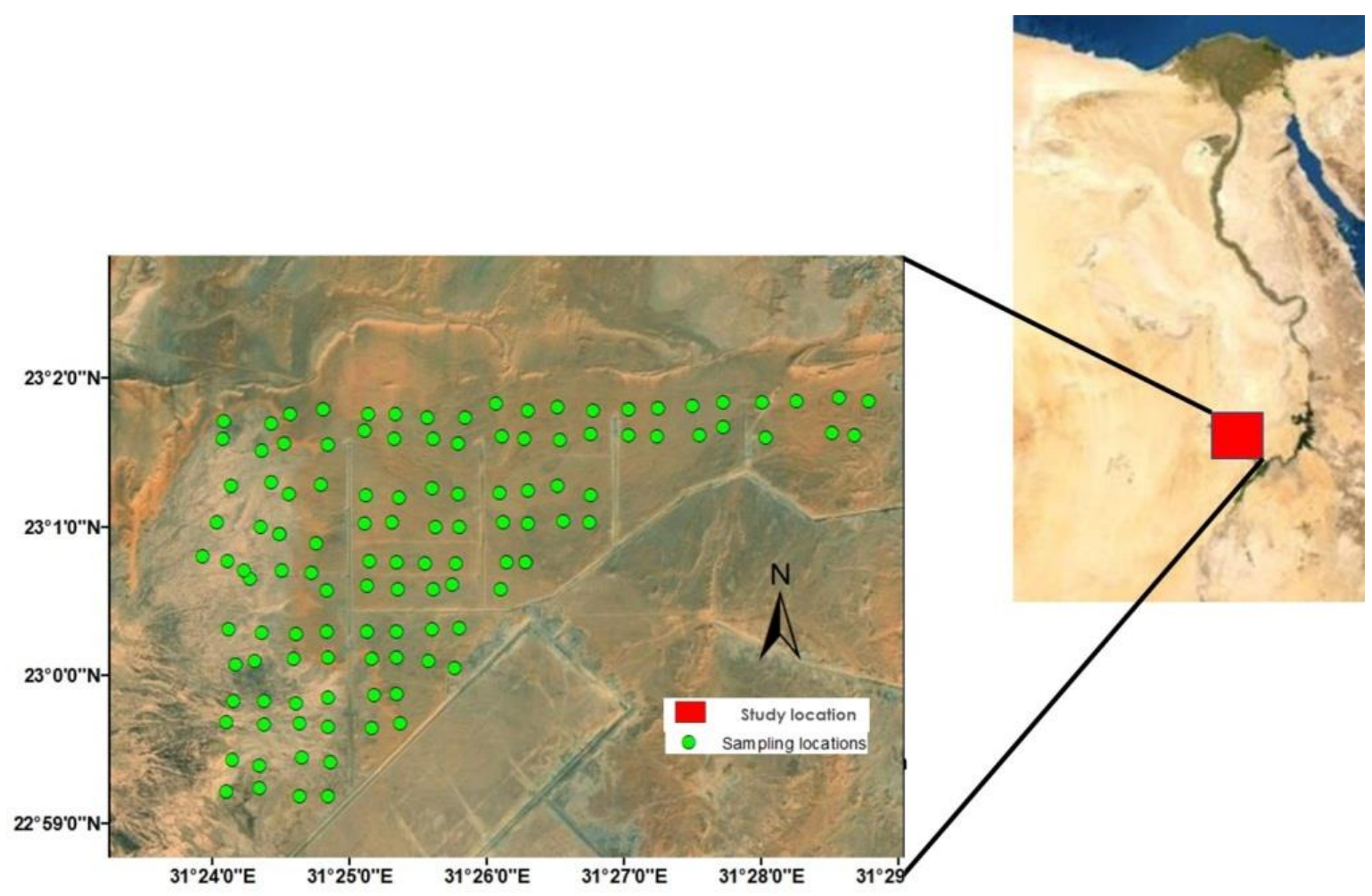

Fig 1. Soil sampling location map of the study area

Table 1. The Analytical Spectral Device Field Spec spectral specifications

\begin{tabular}{|c|c|}
\hline $\begin{array}{c}\text { Spectral Range } \\
(\mathbf{n m})\end{array}$ & $\mathbf{3 5 0 - 2 5 0 0}$ \\
\hline Resolutions (Spectral) & $3: 700$ \\
$(\mathrm{~nm})$ & $8.5: 1400$ \\
& $6.5: 2100$ \\
\hline Sampling Intervals & $1.4: 350-1050$ \\
$(\mathrm{~nm})$ & $2: 1000-2500$ \\
\hline
\end{tabular}

For each soil sample, triplicate readings were recorded, and then a spectral reflectance of a reference white panel was recorded. For each soil sample the deviation of root-mean squares (RMSD) of the three replicates readings was averaged $\pm 0.12 \%$ reflectance.

The hyperspectral data that collected in the laboratory were then employed to derive spectral variables that could characterize variability of the soil salinity (Abd-Elwahed 2005 and Di et al 2010).

\subsection{Statistical Analysis}

The data were analyzed in JMP_(SAS) software (Jones and Sall, 2011). In order to recognize the best wave zone correlate with salinity, linear regression analysis and least significant differences test (LSD and Tukey-HSD for honest significant difference) were performed. They were used to check wherever the difference between data clusters. (McDonald 2014).

The relationship between ECe and the spectral reflectance, that resampled to Landsat 8 bands; blue $(450-510 \mathrm{~nm})$, green $(530-570 \mathrm{~nm})$, red $(640-690 \mathrm{~nm})$, NIR (850-880 nm), SWIR1 (1570-1670 nm) and SWIR2 (2110-2290 nm), were examined. According to Medjahed et al (2016) regression model creation mainly relies on band selection.

Least significant differences (LSD) are computed according to Williams and Abdi (2010) methodology. The mean reflectance spectrum range of each spectral band were compared using Tukey's HSD was established in response to the LSD test.

\subsection{PLSR Modeling}

In spite of the fact that hyperspectral data include huge amount of information, managing and processing this type of data introduce some challenges related to redundancy elimination. Partial-least-squares regression (PLSR) has been used in several scientific fields to create linear models between multivariate information, particularly when dealing with a huge 
number of data points. PLSR regression is a data handling approach that often used to realize relationships between two data groups. It uses a linear multivariate model to forecast one data group using the measured values of the other group. PLSR looks for maximizing the covariance between the two data groups.

Before creating the model, one of the most important steps is selection of informative spectral bands among the enormous range of hyperspectral data. Two steps were applied to reduce the input band numbers. The first step was resampling of spectral resolution from 1-nm of the two bands (SWIR1 and SWIR2) to become 10-nm. The second one was using PLS-stepwise band removal/selection approach to select the most informative bands. According to Jin and Wand (2019), the stepwise-PLS approach was optimal among four approaches to identify informative bands to estimate leaf chlorophyll content.

In the current investigation The PLSR modeling was applied; to create a soil salinity estimation model, using JMP_(SAS) software (Jones and Sall, 2011). The spectral reflectance values along with the measured soil ECe data of 90 soil samples were used for modeling ( 75 samples as training set and 15 samples as validation set).

\section{Results and Discussion}

The data in Table 2 revealed that ECe values in the studied soil samples ranged between 0.52 and $89.04 \mathrm{dS} \mathrm{m}^{-1}$ with a mean value $16.02 \mathrm{dS} \mathrm{m}^{-1}$, the standard deviation was 18.64 and the CV\% was $116.34 \%$.

Table 2. The statistics (descriptive) of soil salinity (ECe) values

\begin{tabular}{|c|c|c|c|c|c|c|c|}
\hline Statistics & Min. & Max. & Mean. & SD & CV \% & Skewness & Kurtosis \\
\hline $\begin{array}{c}\text { ECe } \\
\left(\mathrm{dS} \mathrm{m}^{-1}\right)\end{array}$ & 0.52 & 89.04 & 16.02 & 18.64 & 116.34 & 2.02 & 4.17 \\
\hline
\end{tabular}

The spectral signature pattern for the 90 soil samples (four ECe classes) and the average reflectance for each ECe class are shown in Fig 2. The reflectance pattern followed the same style; as though, the soil samples with higher salinity content has higher reflectance values.

The spectral reflectance curves have similar trend, increasing the wavelength $(\lambda)$ increased the reflectance. The reflectance in visible region $(400$ $-700 \mathrm{~nm}$ ) was lowest that can be explained according to Mahajan et al (2021) by the presence of minerals that contain iron oxide which absorb short wavelengths (less than $0.54 \mu \mathrm{m}$ ). The variations amongst the different studied soil salinity were minor.

Three spectral absorption concave features were denoted around 1400 and 1900 and $2200 \mathrm{~nm}$. According to several researchers (Ma and Fan 2020 and Das et al 2021) the first two absorption features are linked to the water content, while the feature around (2200 $\mathrm{nm}$ ) is related to the $\mathrm{OH}^{-}$groups in soil clay and organic matter contents (Ben-Dor 2002, Sun et al 2018, Angelopoulou et al 2020v Wang et al 2021). These concave absorption features increase with increasing ECe (salinity). The highest spectral reflectance values were mostly located between 1300-1800 nm (SWIR2 spectral region).

To find out the best spectral bands for sensing different soil salinity levels, certain statistical processes were employed on the measured spectral reflectance. The results of regression analysis $\left(\mathrm{R}^{2}\right.$ values shown in Table 3) showed that the highest obtained $\mathrm{R}^{2}$ values for each salinity class were $0.662,0.633,0.594$ and 0.706 for SWIR1, Blue, SWIR1 and SWIR1, respectively. These results agree with those of Wang et al (2019), who used the SWIR bands in salinity detection index to map soil salinity. Tukey's test concluded prominence discrepancy among the four studied salinity classes compared with all other spectral zones for every mean, maximum and minimum of reflectance (Fig 3). The results revealed that SWIR1 and SWIR2 were the most favorable zones to discriminate among the four studied salinity classes followed by red, while blue, green and NIR were inadequate for spectral discrimination.

The low salinity levels (0-2) show real dissimilar reflectance in all six spectral regions.

In general, the results of Tukey's HSD displayed that both SWIR spectral zones (1 and 2) were the most sensitive spectral region to discernment between the studied soil salinity levels followed by red band. These results agree with the previously obtained results from regression analysis. This result is steady with several previous and recent studies that suggest using the spectral reflectance zone ranging between 1000 and $2500 \mathrm{~nm}$ to study soil salinity and discriminate between different soil salinity levels (El-Battay et al 2017, Bannari et al 2018, Sahbeni 2021) stated that the saline soil show indicative features in the shortwave infrared band between 1000 to $2500 \mathrm{~nm}$.

\section{PLSR model for Soil Salinity}

PLSR was employed to figure out the best prediction model of soil ECe based on the soil reflectance values in both SWIR1 and SWIR2 spectral zones. The result of the PLSR-model is shown in Fig 4. 

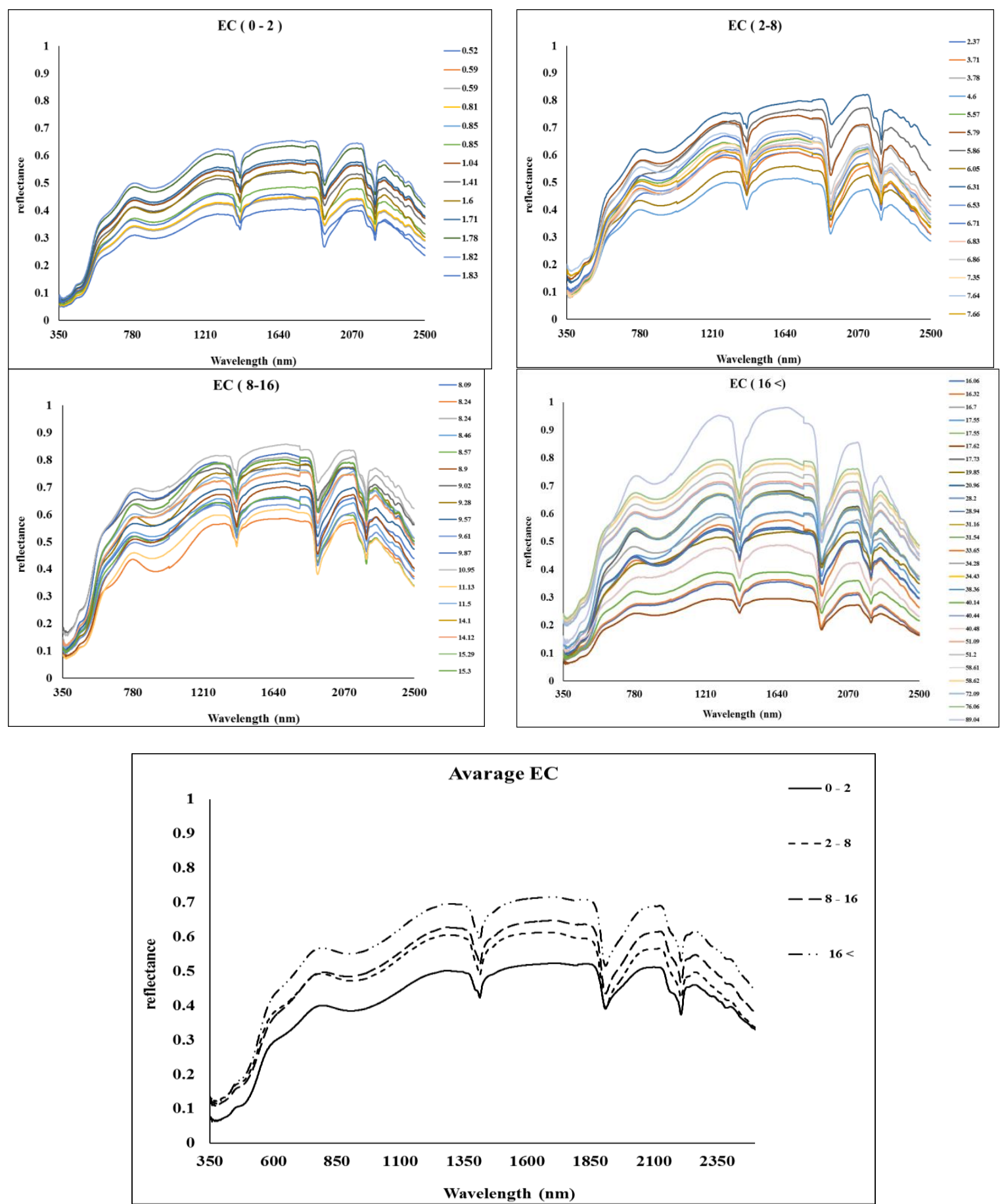

Fig 2. The Spectral signatures for the collected soil samples with various ECe levels and its average spectrum

Table 3. The $\mathrm{R}^{2}$ values collected from the regression analysis between reflectance values and ECe.

\begin{tabular}{|c|c|c|c|c|}
\hline \multirow{2}{*}{ Spectral band (range) } & $\mathbf{0 - 2} \mathbf{d S m}^{-1}$ & $\mathbf{2 - 8} \mathbf{d S m}^{-1}$ & $\mathbf{8 - 1 6} \mathbf{d S m}^{-1}$ & $\mathbf{1 6}<\mathbf{d S m}^{-1}$ \\
\cline { 2 - 5 } & \multicolumn{4}{|c|}{$\mathbf{R}^{\mathbf{2}}$} \\
\hline Blue (450-510 nm) & 0.574 & 0.433 & 0.168 & 0.548 \\
Green (530-570 nm) & 0.547 & 0.094 & 0.321 & 0.471 \\
Red (640-690 nm) & 0.617 & 0.251 & 0.492 & 0.407 \\
NIR (850-880 nm) & 0.338 & 0.359 & 0.417 & 0.396 \\
SWIR1 (1570-1670 nm) & 0.662 & 0.309 & 0.594 & 0.706 \\
SWIR2 (2110-2290 nm) & 0.569 & 0.533 & 0.017 & 0.305 \\
\hline
\end{tabular}


Arab Univ J Agric Sci (2021) 29 (3) 943-952

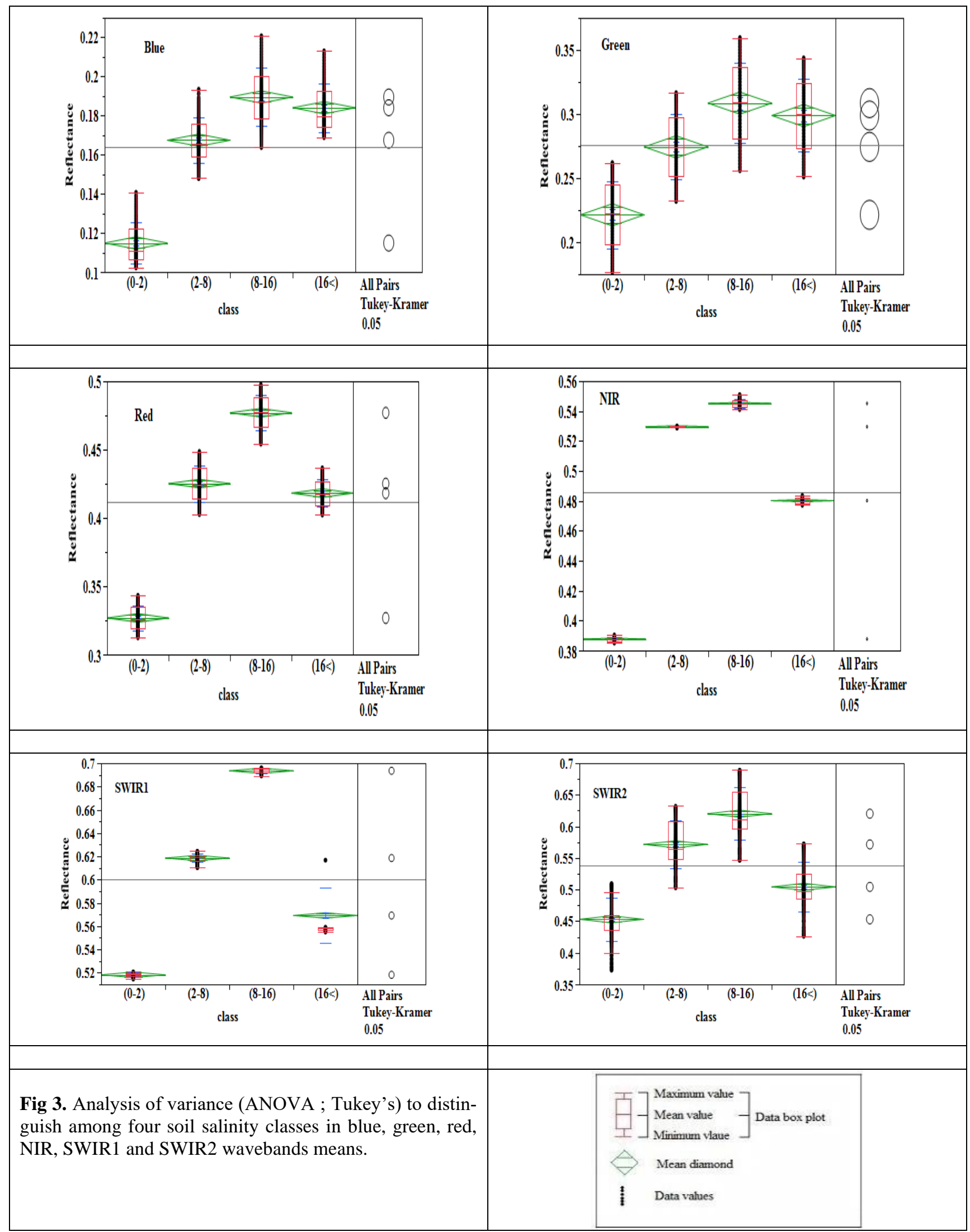


Arab Univ J Agric Sci (2021) 29 (3) 943-952
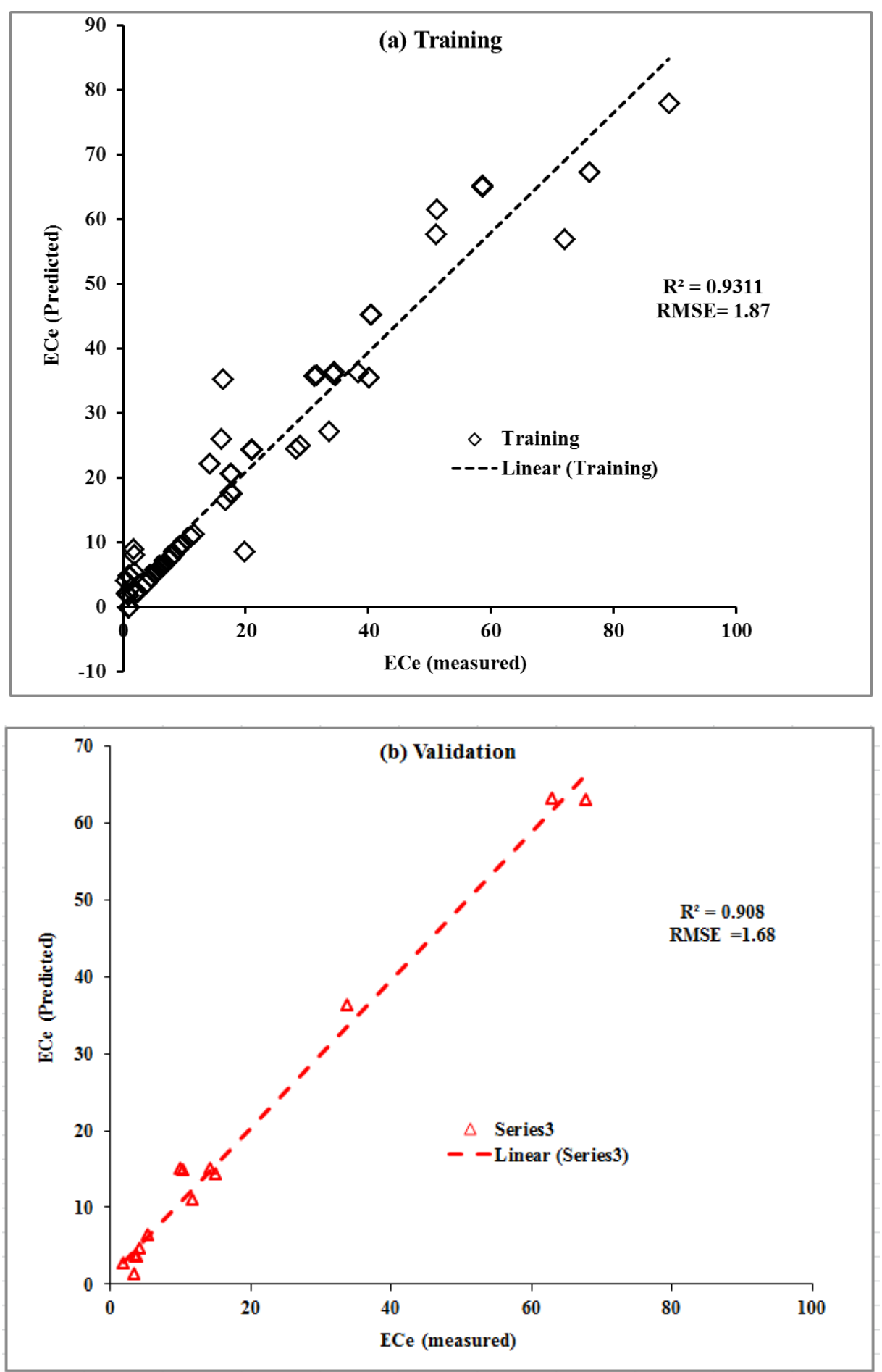

Fig 4. Scatterplot for Predicted soil ECe values using PLSR-Model vs. measured values. (a) 75 samples training set; (b) 15 samples validation set.

It could be verified that, hyperspectral data in SWIR range can effectively distinguish between various soil ECe values of the studied soil samples. The prediction model for soil ECe showed high correlation $\left(\mathrm{R}^{2}\right)$ for both training and validation groups 0.93 and 0.908 , respectively. Meanwhile, ECe showed low RMSE (1.87 and 1.67) between predicted and measured soil EC values for both training and validation groups, respectively. In the current study, the linear prediction model showed a good ability for the soil salinity prediction. These results agree with the results of Farifteh et al (2007) and Zeng et al (2018) who considered the PLSR as a valuable model over other non-linear models for soil salinity prediction. They found similar accuracies between PLSR-Model and other models. But, 
it is easier and consume less time for creation. Instead, some investigations (Mahajan et al 2021 and Das et al 2021) stated that non-linear prediction models gave better results under their experimental conditions. It could be concluded that using PLSR model to develop soil ECe (salinity) detection, prediction and mapping using hyperspectral remote sensing data is suggested.

\section{Conclusions}

It could be concluded from the results of the current study that hyper-spectral remote sensing displayed adequate capability to study, distinguish and predict soil salinity in various levels. Increasing soil salinity levels increased its reflectance for the whole spectrum (350 -2500 nm). The most sensitive wavelengths for soil salinity prediction were identified to be in SWIR region (1570 -2290 $\mathrm{nm})$. The reflectance values in these wave bands exhibited a salinity related features to predict soil salinity. Multivariate PLSR-modeling approach using SWIR bands were found good for soil salinity (ECe) prediction for. The advantages of utilizing hyperspectral information in soil salinity forecast are the lower costs compared to the conventional field-based methods and simplicity of using these models on satellite image for salinity mapping. It is proposed that these prediction models subject more investigations and prior to employment in soil mapping.

\section{References}

Abd-Elwahed M (2005) Assessment of soil salinity problems in agricultural areas through spatial and temporal remote sensing. PhD Dissertation, Univ of Arizona, USA.

Aldabaa A, Weindorf D, Chakraborty S, Sharma A, Li B (2015) Combination of proximal and remote sensing methods for rapid soil salinity quantification. Geoderma 239, 34-46.

https://doi.org/10.1016/j.geoderma.2014.09.011

Angelopoulou T, Balafoutis A, Zalidis G, Bochtis D (2020) From laboratory to proximal sensing spectroscopy for soil organic carbon estimationa review. Sustainability 12, p.443.

https://doi.org/10.3390/su12020443

Bannari A, El-Battay A, Bannari R, Rhinane H (2018) Sentinel-MSI VNIR and SWIR bands sensitivity analysis for soil salinity discrimination in an arid landscape. Remote Seningsing 10, 855 . https://doi.org/10.3390/rs10060855
Ben-Dor E (2002) Quantitative remote sensing of soil properties. Advances in Agronomy 75, 173-244. DOI:10.1016/S0065-2113(02)75005-0

Ben-Dor E, Patkin K, Banin A, Karnieli A (2002) Mapping of several soil properties using DAIS-7915 hyperspectral scanner data-a case study over clayey soils in Israel. International Journal of Remote Sensing 23, 1043-1062.

https://doi.org/10.1080/01431160010006962

Camps-Valls G, Tuia D, Gómez-Chova L, Jiménez S, Malo J (2011) Remote Sensing Image Processing. San Rafael, CA: Morgan and Claypool. https://doi.org/10.2200/S00392ED1V01Y201107IVM0 $\underline{12}$

Csillag F, Pásztor L, Biehl L (1993) Spectral band selection for the characterization of salinity status of soils. Remote Sensing of Environment 43, 231-242. https://doi.org/10.1016/0034-4257(93)90068-9

Das B, Sahoo R, Pargal S, Krishna G, Verma R, Viswanathan C, Sehgal V, Gupta V (2021) Evaluation of different water absorption bands, indices and multivariate models for water-deficit stress monitoring in rice using visible-near infrared spectroscopy. Spectrochimica Acta Part A: Molecular and Biomolecular Spectroscopy 247, 119104.

https://doi.org/10.1016/j.saa.2020.119104

Dehaan R, Taylor G (2002) Field-derived spectra of salinized soils and vegetation as indicators of irrigation-induced soil salinization. Remote Sensing of Environment, 80, 406-417.

DOI:10.1016/S0034-4257(01)00321-2

Di W, Zhang L, Zhang D, Pan Q (2010) Studies on hyperspectral face recognition in visible spectrum with feature band selection. IEEE Transactions on Systems, Man, and Cybernetics - Part A: Systems and Humans,. 40, 1354-1361, Nov. 2010,

DOI:10.1109/TSMCA.2010.2052603

Dwivedi R, Sreenivas K (1998) Delineation of saltaffected soils and waterlogged areas in the IndoGangetic plains using IRS-1C LISS-III data. International Journal of Remote Sensing, 19, 2739-2751. https://doi.org/10.1080/014311698214488

El-Battay A, Bannari A, Hameid N, Abahussain A (2017) Comparative Study among Different SemiEmpirical Models for Soil Salinity Prediction in an Arid Environment Using OLI Landsat-8 Data. Advanced Remote Sensing 6, 23-39.

DOI: 10.4236/ars.2017.61002. 
Farifteh J, Farshad A (2002) Remote sensing and modelling of topsoil properties, a clue for assessing land degradation. In IUSS Congress, BKK, Thailand.

Farifteh J, Van der Meer F, Atzberger C, Carranza E (2007) Quantitative analysis of salt-affected soil reflectance spectra: A comparison of two adaptive methods (PLSR and ANN). Remote Sensing of. Environment 110, 59-78.

DOI:10.1016/j.rse.2007.02.005

Hu J, Peng J, Zhou Y, Xu D, Zhao R, Jiang Q, Fu T, Wang F, Shi Z (2019) Quantitative estimation of soil salinity using UAV-borne hyperspectral and satellite multispectral images. Remote Sensing 11, 736. https://doi.org/10.3390/rs11070736

Jackson M (1967) Soil Chemical Analysis Prentice. Hall of India Pvt Ltd, New Delhi, 498.

Jin J, Wang Q (2018) Selection of informative spectral bands for PLS models to estimate foliar chlorophyll content using hyperspectral reflectance. IEEE Transactions on Geoscience and Remote Sensing, 57, 3064-3072.

DOI:10.1109/TGRS.2018.2880193

Jones B, Sall J (2011). JMP statistical discovery software. Wiley Interdisciplinary Reviews: Computational Statistics 3,188-194.

https://doi.org/10.1002/wics.162

Ma Y, Fan X (2020) Detection and analysis of soil water content based on experimental reflectance spectrum data. Asia-Pacific Journal of Chemical Engineering 15, e2507. DOI:10.1002/apj.2507

Mahajan G, Das B, Gaikwad B, Murgaonkar D, Desai A, Morajkar S, Patel K, Kulkarni R (2021) Monitoring properties of the salt-affected soils by multivariate analysis of the visible and nearinfrared hyperspectral data. Catena 198, 105041. https://dx.doi.org/10.1016/j

McDonald J (2014) Handbook of Biological Statistics, 3rd ed. Sparky House Publishing, Baltimore, Maryland.

Medjahed S, Saadi T, Benyettou A, Ouali M (2016) Microcanonical annealing and threshold accepting for parameter determination and feature selection of support vector machines. Journal of Computing and Information 24, 369-382. https://doi.org/10.20532/cit.2016.1003342.
Minu S, Shetty A, Gopal B (2016) Review of preprocessing techniques used in soil property prediction from hyperspectral data. Cogent Geoscience 2, 1145878.

https://doi.org/10.1080/23312041.2016.1145878

Mougenot B, Pouget M, Epema G (1993) Remote sensing of salt affected soils. Remote sensing Review 7, 241-259.

https://doi.org/10.1080/02757259309532180

Pessoa L, Freire M, Wilcox B, Green C, De Araújo R, De Araújo Filho J (2016) Spectral reflectance characteristics of soils in northeastern Brazil as influenced by salinity levels. Environ monitoring and assessment 188, 1-11.

DOI:10.1007/s10661-016-5631-6

Pimstein A, Karnieli A, Bansal S, Bonfil D (2011) Exploring remotely sensed technologies for monitoring wheat potassium and phosphorus using field spectroscopy. Field Crop Research 121, 125-135. DOI:10.1016/j.fcr.2010.12.001

Poggio L, Gimona A (2017) Assimilation of optical and radar remote sensing data in 3D mapping of soil properties over large areas. Science of the Total Environment 579, 1094-1110.

https://doi.org/10.1016/j.scitotenv.2016.11.078

Richards J, Jia X (2006) Remote Sensing Digital Image Analysis: An Introduction. New York; Berlin, Germany; Heidelberg, Germany: Springer-Verlag, DOI:10.1007/978-3-642-30062-2

Sahbeni G (2021) Soil salinity mapping using Landsat 8 OLI data and regression modeling in the Great Hungarian Plain. SN Applied Sciences 3, 1-13. DOI:10.1007/s42452-021-04587-4.

Schreiner S, Culibrk D, Bandecchi M, Gross W, Middelmann W (2021) Soil monitoring for precision farming using hyperspectral remote sensing and soil sensors. Automatisierungstechnik 69, 325-335.

https://doi.org/10.1515/auto-2020-0042

Singh R, Setia R, Verma V, Arora S, Kumar P, Pateriya B (2017) Satellite remote sensing of salt-affected soils: Potential and limitations. Journal of Soil and Water Conservation 16, 97-107. DOI:10.5958/2455-7145.2017.00015.7

Sun W, Zhang X, Sun X, Sun Y, Cen Y (2018) Predicting nickel concentration in soil using reflectance spectroscopy associated with organic matter and clay minerals. Geoderma 327, 25-35.

DOI:10.1016/j.geoderma.2018.04.019 
Wang C, Qiao X, Li G, Feng M, Xie Y, Sun H, Zhang M, Song X, Xiao L, Anwar S, Yang W (2021) Hyperspectral estimation of soil organic matter and clay content in loess plateau of China. Agronomy Journal 113, 2506-2523. https://doi.org/10.1002/agj2.20700

Wang J, Ding J, Yu D, Ma X, Zhang Z, Ge X, Teng D, Li X, Liang J, Lizaga I., Chen X (2019) Capability of Sentinel-2 MSI data for monitoring and mapping of soil salinity in dry and wet seasons in the Ebinur Lake region, Xinjiang, China. Geoderma 353, 172-187.

https://doi.org/10.1016/j.geoderma.2019.06.040
Williams L, Abdi H (2010) Fisher's least significant difference (LSD) test, in Encyclopedia of Research Design. Encyclopedia of research design 218, 840853.

Xu Y, Smith S, Grunwald S, Abd-Elrahman A, Wani S, Nair V (2018) Estimating soil total nitrogen in smallholder farm settings using remote sensing spectral indices and regression kriging. Catena 163, 111122. https://doi.org/10.1016/j.catena.2017.12.011

Zeng W, Zhang D, Fang Y, Wu J, Huang J (2018) Comparison of partial least square regression, support vector machine, and deep-learning techniques for estimating soil salinity from hyperspectral data. Journal of Applied Remote Sensing 12, p. 022204. https://doi.org/10.1117/1.JRS.12.022204 